\title{
Effects of harvest intensity on the marketable organ yield, growth and reproduction of non-timber forest products (NTFPs): implication for conservation and sustainable utilization of NTFPs
}

\author{
Ting Zhang ${ }^{1,2+}$, Lizhong $\mathrm{Yu}^{1,2 \dagger}$, Yuan Man $^{3}$ and Qiaoling $\mathrm{Yan}^{1,2^{*}}$
}

\begin{abstract}
Background: Non-timber forest products (NTFPs) are an important part of forest biodiversity, and the subsistence and trade of local people, especially in less developed countries. Because of the high ecological and economic value, NTFPs have faced the problem of over-exploitation, and the key to solve this problem is to determine the feasible way of sustainable utilization of NTFPs. Harvest intensity is one of the most important and easily controlled utilization factors, which can greatly influence the plant individual survival, growth and reproductive performances, and even the population structure and dynamics. Therefore, we chose two common and important NTFPs species with different marketable parts (i.e., Acanthopanax senticosus with tender leaves and Aralia elata with tender buds) as our study objects. Aiming to determine the optimum harvest intensity for sustainably utilizing both NTFPs species, five levels of harvest intensity treatments (i.e., control, light, medium, high and severe) were designed to assess the effects of harvest intensity on their marketable organ yield, plant growth and reproductive performances.

Results: The biomass growth rates of marketable organ and plant growth of $A$. senticosus under light harvest intensity treatment were significantly higher than those under other harvest intensities. The plant height growth and 1000-seed weight of $A$. elata under severe harvest intensity treatment were significantly lower than those under control treatment.

Conclusions: The light harvest intensity with $25 \%$ leaf removal and the high harvest intensity with all terminal buds harvested are the optimum harvest intensity to maintain the sustainable utilization of $A$. senticosus and $A$. elata, respectively. These findings could provide managers with basic but practical guidance for making decisions about the sustainable harvest management plan for the cultivated NTFPs species, and further provide a theoretical basis for managers to establish the harvest regulations for wild NTFPs species. Consequently, the local residents or communities can improve their income while ensure the sustainable development of wild NTFPs.
\end{abstract}

\footnotetext{
* Correspondence: qlyan@iae.ac.cn

${ }^{\dagger}$ Ting Zhang and Lizhong Yu contributed equally to this work.

${ }^{1}$ CAS Key Laboratory of Forest Ecology and Management, Institute of Applied

Ecology, Shenyang 110016, China

${ }^{2}$ Qingyuan Forest CERN, Chinese Academy of Sciences, Shenyang 110016,

China

Full list of author information is available at the end of the article
}

() The Author(s). 2021 Open Access This article is licensed under a Creative Commons Attribution 4.0 International License, which permits use, sharing, adaptation, distribution and reproduction in any medium or format, as long as you give appropriate credit to the original author(s) and the source, provide a link to the Creative Commons licence, and indicate if changes were made. The images or other third party material in this article are included in the article's Creative Commons licence, unless indicated otherwise in a credit line to the material. If material is not included in the article's Creative Commons licence and your intended use is not permitted by statutory regulation or exceeds the permitted use, you will need to obtain permission directly from the copyright holder. To view a copy of this licence, visit http://creativecommons.org/licenses/by/4.0/. 
Keywords: Araliaceae family, Non-timber forest products, Sustainable utilization, Harvest intensity, Plant regeneration, Marketable organ yield

\section{Background}

Non-timber forest products (NTFPs) are defined by Global Forest Resources Assessments (FRA) 2020 as "goods derived from forests that are tangible and physical objects of biological origin other than wood" (FAO 2020a). NTFPs are an important part of forest biodiversity and the subsistence and trade of local people (Ros-Tonen 2000). According to FRA 2020, information on NTFPs is reported in 124 countries and territories, which account for $73 \%$ of the global forest area and have about 6.2 billion urban and rural people (FAO 2020a). Thus, millions of households around the world depend heavily on NTFPs for livelihoods, and approximately $80 \%$ of the people from developing countries takes advantage of NTFPs for health and nutritional needs (FAO 2020b). In addition, the NTFPs also contribute to subsistence needs and cash income of rural and urban residents (Wahlén 2017; Nguyen et al. 2021). Moreover, NTFPs also can be seen as important export commodities, and at least 150 kinds of NTFPs play a significant role in the international trade (FAO 2020b). Thus, the importance of NTFPs for rural and urban residents' livelihood, especially in developing countries, has been widely recognized (Chou 2019).

The history of human beings harvesting valuable NTFPs has been lasting for thousands of years. Harvesting of NTFPs plays an important role for local people in improving cash income and providing subsistence needs in less developed countries (Stanley et al. 2012). Compared with timber harvest, the NTFPs harvest does less damage to forest ecosystems and contributes more to conserve biodiversity and ecosystem function (Gaoue and Ticktin 2008; Hernández-Barrios et al. 2014). Because of the high ecological and economic value, the problem of NTFPs being over-exploited has begun to show up in recent years (Belcher and Schreckenberg 2007). Concerns over the NTFPs overexploitation has led to a growing number of studies on the sustainable utilization of NTFPs (Stanley et al. 2012; HernándezBarrios et al. 2014; Zhu et al. 2019a).

Generally speaking, sustainable harvest of NTFPs refers to NTFPs harvest in such a way that it is not depleted (Lázaro-Zermeño et al. 2011). At present, few generalized rules on the response of NTFPs to harvest have been summarized due to the widely various harvest effects (e.g., species life forms, harvested parts and harvest intensity) (Schmidt et al. 2011; Rist et al. 2012; Hernández-Barrios et al. 2014). For example, heavy rates of foliage harvest could decrease rates and patterns of reproduction in Khaya senegalensis (Meliaceae), but the impact of debarking or combined debarking and pruning on reproductive performance was not significant (Gaoue and Ticktin 2008). Pentadesma butyracea Sabine (Clusiaceae) seedling and sapling densities were high in low fruit harvest intensity treatment but very low in high fruit harvest intensity treatment (Avocèvou-Ayisso et al. 2009). All these studies were used to provide guidance for the development of sustainable utilization of local NTFPs. Therefore, Ticktin (2004) has put forward in his review that the NTFPs harvest can directly affect the plant individual survival, growth and reproduction, and further has an impact on the population structure and dynamics. Thus, the reasonable harvest manner is considered as the key to determine the sustainable utilization of NTFPs and preserve the NTFPs store.

According to Hernández-Barrios et al. (2014), the sustainable utilization of target NTFPs can be defined as the harvest intensity at which the marketable organs yield is maximized under the constraint that plant regeneration process of each plot is not significantly affected (i.e., compared with control treatment, the growth and reproductive performances are not significantly reduced). Thus, any problem in the process of plant regeneration may affect the successful regeneration of plant. Many previous studies have focused on the effects of harvest intensity (e.g., harvest frequency and harvest proportion) on the plant regeneration processes (e.g., plant marketable organ yield, survival, growth and reproductive performance) (Endress et al. 2006; Gaoue and Ticktin 2008, Hernández-Barrios et al. 2014) and even population structure (Guedje et al. 2007; Schumann et al. 2011). However, most of them only concentrated on the effect of harvest intensity on a certain process of plant regeneration, and lack of the comprehensive analysis on the impact of the whole process of plant regeneration. This may limit our understanding of the sustainable management of NTFPs.

A wide variety of NTFPs distributes in a montane region of Northeast China. The Acanthopanax senticosus (Rupr. Maxim.) Harms and Aralia elata (Miq.) Seem., two species of Araliaceae family with different marketable organs, are recognized as two kinds of the common and dominant NTFPs species in this region. The roots, stems and leaves of $A$. senticosus can be used as medicine to treat a variety of diseases (e.g., coronary heart disease, diabetes, and nervous system diseases, etc.) (Zhou et al. 2018). Moreover, the buds and leaves of $A$ senticosus are valuable wild vegetables with delicious 
taste and high nutritional value, and have been sold in South Korea, Japan and some other countries (Fujikawa et al. 2005). A. elata is known as the "king of wild vegetables" in Northeast China. The buds of $A$. elata are rich in nutrition, and its roots, stems, bark and leaves also can be used as medicine to treat various diseases (e.g., neurasthenia and rheumatoid arthritis, etc.) (Hao et al. 2018). Thus, the $A$. elata is the main wild vegetable for earning foreign exchange through export (Sun et al. 2009; Geng et al. 2013). Therefore, we selected these two kinds of edible and medicinal NTFPs species with high economic value as the objects of our study. However, as two important wild resources for both medicine and food use in China, A. senticosus and A. elata have to face the problems of increasing demand and diminishing storage due to the over-exploitation with disorderly harvest, poor management, and their poor seed regeneration ability (e.g., low seed setting rate, congenital seed dormancy, and low seed germination rate) (Wang and Duanmu 2009; Zhang and Shen 2011). Thus, to improve the marketable organ yield while protecting wild resources, more and more local people and forest managers have tried to develop artificial cultivation and utilization techniques of the two NTFPs species understory (Liu et al. 2011; Hao et al. 2018). At present, the researches on two kinds of NTFPs are mainly focused on cultivation and utilization technology (Luo 2003; Hao et al. 2018), rapid propagation (Han et al. 2008; Qi et al. 2015) and pharmacological action (Zhao et al. 2016). However, few studies have reported the effects of harvest intensity on the complete regeneration processes of wild resources (i.e., including both the subsequent growth and reproduction of NTFPs) (Endress et al. 2006; Hernández-Barrios et al. 2014). Therefore, we took these two Araliaceae species with different harvested parts (leaves and tender buds) to test the influence of harvest intensity (harvest proportion and frequency), and further to find out the optimum harvest intensity to maintain the marketable organ yield and the successful growth and regeneration. We expect that this study can propose practical recommendations (e.g., the optimum harvest intensity) applied in the sustainable utilization and management plan for the Araliaceae species, and further provide supports for the biodiversity conservation by maintaining sustainable utilization of NTFPs worldwide.

\section{Methods}

\section{Study area description}

The field experiment was conducted in Qingyuan Forest CERN, Chinese Academy of Sciences, located within a montane region in Northeast China $\left(41^{\circ} 50^{\prime} \mathrm{N}, 124^{\circ} 47^{\prime}\right.$ E, 500-1100 a.s.l.). The climate of study area is temperate continental monsoon type. The mean annual air temperature is $4.7^{\circ} \mathrm{C}$ and mean annual precipitation is
$810.9 \mathrm{~mm}$, with a rainy summer ( $80 \%$ falls in this season) from June to August (Zhang et al. 2018). The growing season lasts from early April to late October with the frost-free period of 130 days (Lu et al. 2018a; Yan et al. 2019). The soil is a typical brown forest soil, and consists of $25.6 \%$ sand, $51.2 \%$ silt, and $23.2 \%$ clay (Yang et al. 2013).

Secondary forests have become the major forest resources, accounting for $60 \%$ and $72 \%$ of forest area in the entire world and Northeast China, respectively (Longworth and Williamson 2018; Zhu et al. 2019b). In Northeast China, to meet the high demand for timber production, natural secondary forests have gradually been replaced by plantations (Larix gmelinii (Rupr.) Kuzen., Pinus koraiensis Sieb. and Picea koraiensis Nakai) since the 1950s (Lu et al. 2018b), and the temperate secondary forest ecosystem (i.e., mosaic plantation/ natural secondary forest landscapes) has been established. This study area is covered with the typical temperate secondary forest ecosystem ( $\mathrm{Lu}$ et al. 2018a). The dominant tree species in the secondary forest include Fraxinus rhynchophylla Hance, Juglans mandshurica Maxim., Quercus mongolica Fisch. and Acer mono Maxim. etc. (Lu et al. 2018b). There are abundant wild NTFPs in the secondary forest ecosystem, such as Pimpinella brachycarpa (Kom.) Nakai, Aegopodium alpestre Ledeb., A. senticosus, and A. elata. Since 1998, Chinese government has fully implemented the China Natural Forest Protection Project (NFPP) by protecting forests without any management measures and deforestation for natural forests (including primary and secondary forests) (Yu et al. 2011). Local people, who used to make a living by only harvesting timber from the secondary forest ecosystem, must harvest wild NTFPs from forests for livelihood since then. Furthermore, local people also have begun to plant valuable NTFPs (e.g., P. brachycarp, A. senticosus, $A$. elata, etc.) within larch plantations ( $L$. gmelinii) after thinning to raise their revenue, while ensuring the growth of large-diameter timber for larch.

\section{Species description}

Both $A$. senticosus and $A$. elata belong to Araliaceae family, and can regenerate from seeds and sprouts. A. senticosus is a deciduous perennial shrub species usually occurring in the understory of mixed broadleaf-conifer forests or broadleaf forests, cutting land and forest edge in Northeast China. According to the local standard, the leaves of $A$. senticosus with the length of $3-5 \mathrm{~cm}$ are marketable, and the harvest period is lasting from May to August. A. elata is a deciduous perennial dungarunga species, mainly distributed in Northeast China. According to the local standard, the tender buds of $A$. elata with the length of $8-15 \mathrm{~cm}$ are marketable. The harvest 
period of terminal buds is from late April to early May, and the harvest period of lateral buds is in mid-May.

\section{Experiment design}

We selected two larch plantation stands with $A$. senticosus (LP1) and A. elata (LP2) planted understory, respectively in this study, and the basic information of these two experimental stands were shown in Table 1. A complete randomized design was used in each plantation stand. In April 2017, fifteen $5 \mathrm{~m} \times 5 \mathrm{~m}$ plots were established in LP1 and LP2, respectively. Each plot was assigned to one of five harvest intensity treatments (control, light, medium, high and severe). For each species, each harvest intensity treatment had three replicates. The sketch map of study site and experimental design was shown in Fig. 1.

The A. senticosus in LP1 was planted in 2010 with the planting density of 7000 clumps.ha ${ }^{-1}$, and present density was 6500 clumps.ha ${ }^{-1}$ (1-3 individuals/clump). With the management measure of $A$. senticosus, only the tender leaves on the telome were harvested in spring every year, and the interval of fruit harvest was 1-2 years. We defined five harvest intensity treatments of A. senticosus in each plot as follows: 1) the control treatment with $0 \%$ leaf removal; 2) the light harvest intensity treatment with $25 \%$ leaf removal; 3) the medium harvest intensity treatment with $50 \%$ leaf removal; 4) the high harvest intensity treatment with $75 \%$ leaf removal; 5) the severe harvest intensity treatment with $100 \%$ leaf removal (HernándezBarrios et al. 2014).

The A. elata in LP2 was planted in 2003 with the planting density of 6000 individuals.ha ${ }^{-1}$. The management of A. elata was that only tender bud harvest was conducted during the harvest period. In this study, the harvest interval between terminal buds and lateral buds was 10 days. According to the growth characteristics of A. elata (i.e., terminal buds and lateral buds), we defined five harvest intensity treatments in each plot as follows: 1) the control treatment with no tender buds harvested; 2) the light harvest intensity treatment with only $50 \%$ terminal buds harvested; 3) the medium harvest intensity treatment with $50 \%$ terminal buds and $50 \%$ lateral buds harvested; 4) the high harvest intensity treatment with only $100 \%$ terminal buds harvested; 5) the severe harvest intensity treatment with $100 \%$ terminal buds and 100\% lateral buds harvested.

\section{Measurement of marketable organs}

The initial mean height and basal diameter (in April 2017) of A. senticosus and A. elata were 128 and 1.51 $\mathrm{cm}$, and 126.50 and $1.70 \mathrm{~cm}$, respectively. The tender leaves of $A$. senticosus and buds of $A$. elata were harvested in each plot according to the harvest intensity treatments in May 2017 and 2018, respectively. The samples were transported to laboratory, and then were dried at $65^{\circ} \mathrm{C}$ for at least $72 \mathrm{~h}$ until a constant weight was achieved. The biomass of $A$. senticosus tender leaves per unit area was calculated as the dry mass of tender leaves in each plot divided by each plot area. The biomass of $A$. elata tender buds per plant was calculated as the dry mass of buds in each plot divided by the number of $A$. elata in each plot. Biomass growth rate (BGR) of tender leaves or buds was calculated as follows:

$$
\operatorname{BGR}(\%)=\frac{B_{2}-B_{1}}{B_{1}} \times 100 \%
$$

where $B_{1}$ and $B_{2}$ are the biomass of $A$. senticosus tender leaves per unit area or the biomass of $A$. elata tender buds per plant in 2017 and 2018, respectively.

All individuals in these plots were labeled for the following measurements.

Table 1 Basic information of two experimental stands of larch plantations. DBH: diameter at breast height. LP1: Larch plantation with Acanthopanax senticosus planted understory; LP2: Larch plantation with Aralia elata planted understory

\begin{tabular}{lll}
\hline Characteristics & LP1 & LP2 \\
\hline Forest type & Larch plantation & Larch plantation \\
Slope $\left(^{\circ}\right)$ & $15-20$ & $10-25$ \\
Stand age (year) & 48 & 49 \\
Stand density (per ha) & 150 & 250 \\
Canopy density (\%) & 50 & 50 \\
Mean height (m) & 22.4 & 22.4 \\
Mean DBH (cm) & 39 & 35 \\
Species planted understory & Acanthopanax senticosus & Aralia elata \\
The total number of plots & 15 (3 replicates of each harvest intensity) \\
Measurement cycle for each harvest intensity treatment & Two cycles for harvest and growth \\
\end{tabular}




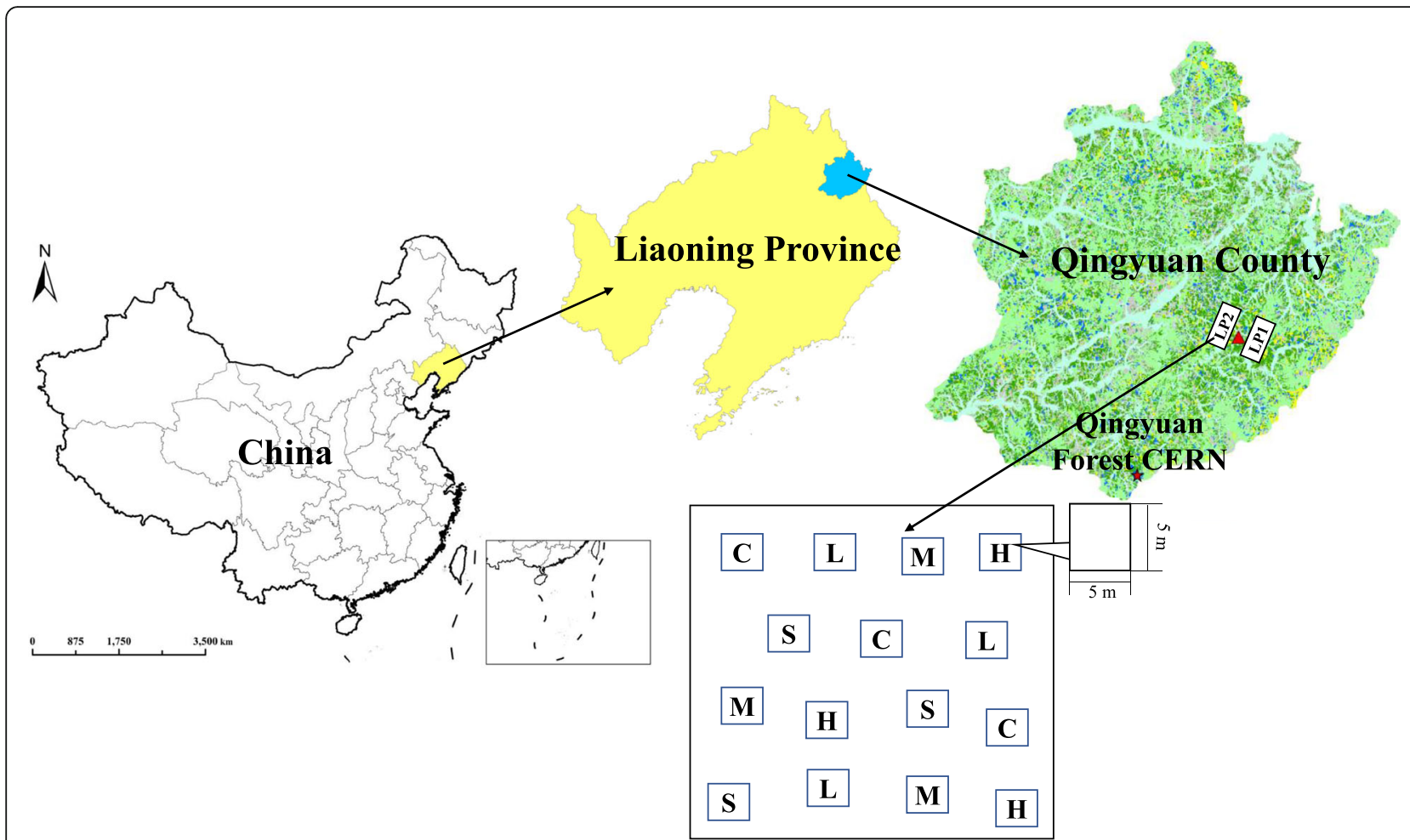

Fig. 1 The sketch map of study site and experimental design. C: control treatment plot; L: light harvest intensity treatment plot; M: medium harvest intensity treatment plot; $\mathrm{H}$ : high harvest intensity treatment plot; $\mathrm{S}$ : severe harvest intensity treatment plot

\section{Growth measurement}

In October 2017 and 2018, we measured the height and basal diameter of each individual plant of $A$. senticosus or A. elata in each plot. The height growth (HG) and basal diameter growth (BDG) were calculated as follows:

$$
\begin{aligned}
& \mathrm{HG}(\mathrm{cm})=H_{2}-H_{1} \\
& \operatorname{BDG}(\mathrm{cm})=D_{2}-D_{1}
\end{aligned}
$$

where $H_{1}$ and $D_{1}$ are the height and basal diameter of individual plant in 2017; $H_{2}$ and $D_{2}$ are the height and basal diameter of individual plant in 2018.

The measurements of each plant within the same plot were averaged to represent the status of mean height growth and basal diameter growth.

\section{Reproduction measurement}

In June 2018, we distinguished the sprouts and seedlings in each plot after experiment treatment conducted, and then counted and recorded the number of sprouts and seedlings in each plot, respectively. This survey was conducted only once in June 2018. Sprouts regenerated from plant root and grew rapidly, with a height ranging from 10 to $80 \mathrm{~cm}$. Compared with the sprouts, the growth of the seedlings from seeds was slower, with a height ranging from 5 to $30 \mathrm{~cm}$. And then, in October 2018, we harvested the fruits of two species. All the harvested fruits were transported to laboratory, and then soaked in water and scrubbed off the pericarp and pulp (Tian et al. 1999). The processed fruits were naturally dried. 1000 seeds were randomly selected and weighed. The 1000-seed weight data of each plant within the same plot were averaged to represent the 1000 -seed weight of each plot.

\section{Data analysis}

A one-way analysis of variance (one-way ANOVA) was used to test the effect of harvest intensity treatment on biomass growth rate, height growth, basal diameter growth, number of sprouts and seedlings, and 1000-seed weight for $A$. senticosus and A. elata. Tukey's post hoc tests were used to examine the differences among the harvest intensity treatment levels. All of the statistical tests were performed using $\mathrm{R}$ version 3.5.3, and significance was examined at the level $P<0.05$. For each variable in the same plot, the average values $( \pm$ S.E.) for each species were presented in the figures and tables.

\section{Results}

Biomass growth rate of marketable organs

The biomass growth rate (BGR) of $A$. senticosus tender leaves was significantly affected by the harvest intensity $(P=0.003)$, but the BGR of $A$. elata buds was independent of the harvest intensity $(P=0.212)$ (Table 2$)$. The 
Table 2 One-way ANOVA test for the effects of harvest intensity on the biomass growth rate of marketable organs, height growth, basal diameter growth, the number of sprouts and seed weight of Acanthopanax senticosus and Aralia elata. Significant effects $(P<0.05)$ are bolded

\begin{tabular}{llllllll}
\hline Parameters & $d \boldsymbol{f}$ & \multicolumn{2}{l}{ Acanthopanax senticosus } & & \multicolumn{2}{c}{ Aralia elata } \\
\cline { 3 - 4 } & & $\boldsymbol{F}$ & $\boldsymbol{P}$ & & $\boldsymbol{F}$ & $\boldsymbol{P}$ \\
\hline Biomass growth rate & 3 & 11.520 & $\mathbf{0 . 0 0 3}$ & & 1.878 & 0.212 \\
Height growth & 4 & 21.260 & $<\mathbf{0 . 0 0 1}$ & & 3.939 & $\mathbf{0 . 0 3 6}$ \\
Basal diameter growth & 4 & 127.300 & $<\mathbf{0 . 0 0 1}$ & & 2.016 & 0.168 \\
Number of sprouts & 4 & 2.571 & 0.103 & & 3.016 & 0.071 \\
Seed weight & 4 & 0.863 & 0.518 & & 3.685 & $\mathbf{0 . 0 4 3}$ \\
\hline
\end{tabular}

BGR of $A$. senticosus tender leaves was significantly promoted by the light harvest treatment $(B G R=163.33 \% \pm$ $21.18 \%)$, but greatly decreased with the increase of harvesting intensity (Fig. 2).

\section{Plant growth}

The harvest intensity significantly affected the height growth (HG) $(P<0.001)$ and basal diameter growth (BDG) $(P<0.001)$ of $A$. senticosus (Table 2$)$. Both HG and BDG of $A$. senticosus showed significantly decreased with the increase of harvest intensity (Fig. 3). Compared with control treatment, the height growth under light, medium, high and severe harvest intensities decreased $10.85 \%, 18.06 \%, 23.32 \%$ and $31.30 \%$, respectively; and the basal diameter growth under light, medium, high and severe harvest intensities decreased 9.76\%, 26.83\%, $39.02 \%$ and $48.78 \%$, respectively (Fig. 3). The HG of $A$. elata was significantly affected by the harvest intensity $(P=0.036)$, but the BDG showed no significant difference among five harvest intensity treatments $(P=$ 0.168) (Table 2). The HG of A. elata in the control treatment was significantly higher than that in the severe harvest intensity treatment (Fig. 3a).

\section{Plant reproduction}

No seedlings regenerated from seeds were found during the investigation after harvest treatments. Thus, only the results of sprouts were shown in this part. The number of sprouts $(P=0.103)$ and the 1000 -seed weight $(P=$ $0.518)$ of $A$. senticosus, and the number of $A$. elata sprouts $(P=0.071)$ showed no significant difference among five harvest intensity treatments (Table 2, Fig. 4). Only the 1000 -seed weight of $A$. elata was significantly affected by the harvest intensity $(P=0.043)$ (Table 2$)$, and the 1000-seed weight of $A$. elata in the control treatment was significantly higher than that in the severe harvest intensity treatment (Fig. 4b).

\section{Discussion}

A. senticosus tender leaves and A. elata tender buds are well-known as two of the wild vegetables with high marketability, and are harvested heavily by local people in the montane region of Northeast China. Our results showed that the response of marketable organ yield, plant growth and reproduction of these two species with different harvested parts to harvest intensity varied significantly. These findings illustrated that although the $A$. senticosus and $A$. elata belong to the same family (i.e., Araliaceae), the different harvested parts also led to different responses of plant characteristics to harvest intensity. Based on the summary of many previous studies, the review of Ticktin (2004) has also reported that the

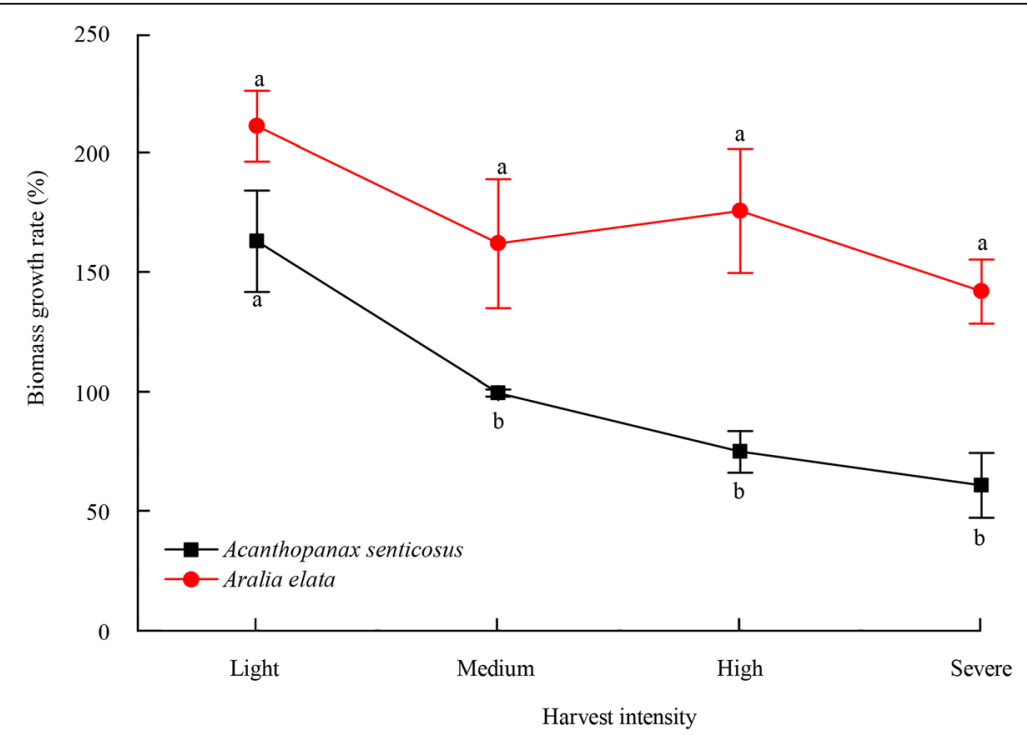

Fig. 2 Biomass growth rate of Acanthopanax senticosus tender leaves and Aralia elata buds in different harvest intensities. The data are presented as the mean \pm S.E.. Different lowercases indicate significant differences $(P<0.05)$ among harvest intensities for the same species 


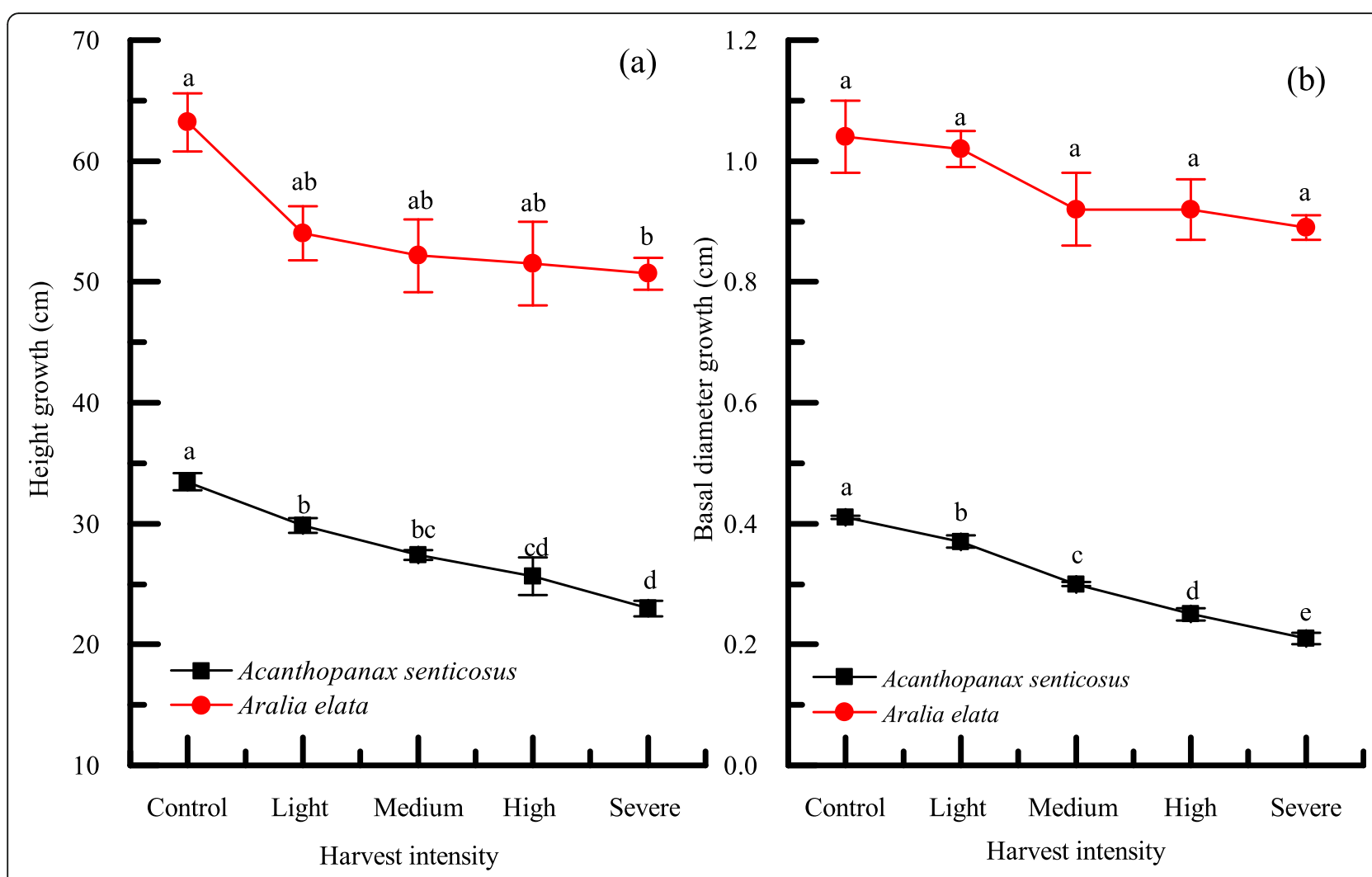

Fig. 3 The height growth (a) and basal diameter growth (b) of Acanthopanax senticosus and Aralia elata in different harvest intensities. The data are presented as the mean \pm S.E.. Different lowercases indicate significant differences $(P<0.05)$ among harvest intensities for the same species

impact of harvest intensity would change with the various harvested parts. Thus, the influence of harvest intensity on plant characteristics should be discussed by specific species.

In this research, harvest activities can lead to the increase of marketable organs yield of both the two Araliaceae species (all BGRs $>0$ ). However, compared with the harvest of $A$. elata tender buds, the effect of harvest intensity on BGR of $A$. senticosus tender leaves is more significant. This may be because leaves are important organs for plant photosynthesis, and the harvest of leaves can directly affect the plant photosynthetic capacity and further affect leaf production, plant growth and reproductive performance (Ticktin 2004; Lázaro-Zermeño et al. 2011; Hernández-Barrios et al. 2014). Our results illustrate that the light harvest intensity ( $25 \%$ of all tender leaves removed) was most beneficial to the promotion of A. senticosus marketable organ yield, but the promotion showed significantly decrease when the harvest intensity was greater than $25 \%$ of all tender leaves. Hernández-Barrios et al. (2014) had explored the sustainability of palm leaves harvesting, and found the palms tolerated up to $50 \%$ leaves harvesting, but higher harvest levels could reduce the leaf production. Our results are partly consistent with theirs because of the interspecies difference. The effect of tender bud harvest on the plant growth and reproduction of NTFPs have hardly been studied so far. We harvested the tender buds of $A$. elata with different intensities, but finally found that there was no significant effect of harvest intensity on the tender bud biomass growth of $A$. elata. This suggests that compared with foliage harvest, bud harvest shows slight influence on the marketable organ growth in subsequent year.

Both horizontal and vertical growth of A. senticosus had significant responses to various harvest intensities, and showed a dramatically trend of decreasing with the increase of harvest intensity. These effects may be because the removal of more leaves can decrease photosynthetic capacity of $A$. senticosus, and further decrease its growth (Endress et al. 2006). Compared with no harvest treatment, the $A$. senticosus plants tolerated up to $25 \%$ tender leaf removal (light harvest intensity) showed a slightest effect on the plant growth among all four harvest intensity levels. The tender buds of $A$. elata are the parts which plant uses for the subsequent height growth in the growing season (Jonsson 2006), and harvesting of terminal buds can stimulate the generation and growth of lateral buds. Therefore, the effect of harvest intensity on the growth of $A$. elata is not so significant as that on 

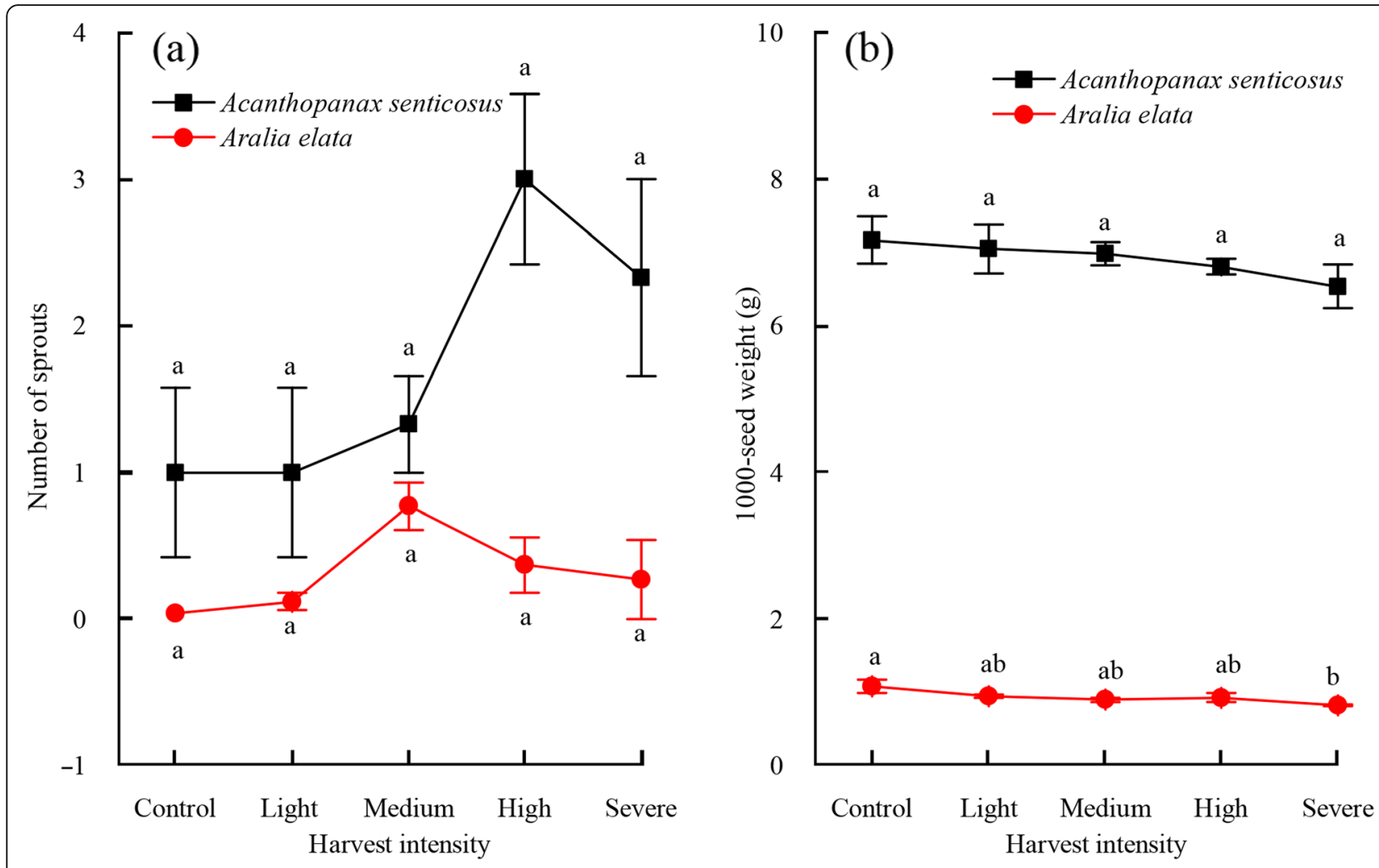

Fig. 4 Number of sprouts (a) and seed weight (b) of Acanthopanax senticosus and Aralia elata in different harvest intensities. The data are presented as the mean \pm S.E.. Different lowercases indicate significant differences $(P<0.05)$ among harvest intensities for the same species

the growth of $A$. senticosus. The height growth of $A$. elata under severe harvest intensity treatment (100\% terminal buds and $100 \%$ lateral buds per plot harvested) was significantly lower than that under no harvest treatment. This fact suggests that harvesting of all tender buds can lead to poor plant growth. The study on the short $A$. elata in the poor condition also has reported the similar result that the increase of harvest intensity could severely weaken the tree vigor and lead to poor plant growth (Geng et al. 2013). Therefore, to maintain the $A$. elata growth while maximizing marketable organ yield (i.e., tender bud yield), the severe harvest intensity with all terminal and lateral tender bud removal should be avoided in the early spring. Moreover, our results also indicated that harvest intensity was more easily to affect the subsequent growth of plant with tender leaves as marketable organs than those with buds as marketable organs.

There has not reached a consensus in the existing studies for the harvest intensity effects of marketable organs on plant productive performance. In present study, the number of sprouts and seed weight of $A$. senticosus and the number of sprouts of $A$. elata were not affected by harvest intensity, but the seed weight of $A$. elata only under the severe harvest intensity treatment was significantly lower than that under the no harvest treatment. Thus, the severe harvest intensity was not conducive to A. elata reproduction. Taking both market value of terminal buds and lateral buds and influence of harvest intensity on the growth and reproduction into consideration, the high harvest intensity with all terminal bud removal and all lateral buds reserve was the optimum harvest intensity for $A$. elata to maintain plant growth while maximizing bud yield. Previous researches also have studied on the effect of marketable organ harvest on the plant reproduction, and results such as the heavy rates of leaves harvest could decrease rates and patterns of reproduction in Khaya senegalensis (Gaoue and Ticktin 2008), leaf-harvesting had a significant impact on the fruit production of Adansonia digitata L. (Schumann et al. 2011) and could reduce the growth and reproductive activity of Chamaedorea radicalis (Endress et al. 2006), and the sprouting ability of Anogeissus leiocarpa significantly increased with higher chopping intensity (Schumann et al. 2011) have been reported. Our results were only partly consistent with these previous studies, this may be due to the interspecies difference and observation interval. The effects of NTFPs harvest in our study are only assessed over 2 years, but the cumulative effects of harvest over 
sufficiently long time are also necessary to assess the effect of harvest on the plant production (Hernández-Barrios et al. 2014).

\section{Conclusions}

The sustainable utilization of target NTFPs in our study are considered as the harvest intensity at which the yield/biomass of marketable organs is maximized under the constraint that growth and reproduction of each plot are not significantly reduced (compared with control treatment). According to this definition, we found that the light level of leaf harvesting (25\% leaf removal) for $A$. senticosus and the high level of tender bud harvesting (only 100\% terminal buds per plots removal) for A. elata are the optimum harvest intensity to maintain the sustainable utilization, respectively. Our results can provide NTFPs managers with basic but practical guidance for making decisions about the sustainable harvest management plan for the cultivated NTFPs species. Furthermore, these findings can also play an important role in the harvest intensity management of these two wild NTFPs species. Local harvesting of the two wild NTFPs is usually disorderly and unregulated, but this harvesting pattern will lead to over-exploitation of NTFPs. Our findings on the optimum harvest intensity of these two NTFPs can provide a theoretical basis for managers to establish the harvest regulations for wild NTFPs species. The managers can supervise the harvesting of wild NTFPs by local communities or residents based on harvest regulations, so that the local residents or communities can improve their income while ensure the sustainable development of wild NTFPs. However, our study only conducted in consecutive 2 years, the sufficiently long-time study should be conducted in the future to assess the long-term effect of harvest on the sustainable utilization of especially the plant production. Moreover, in the further study, a comprehensive perspective in the ecological, economic, social and political analysis for designing sustainable NTFPs harvesting regimes is needed to provide more scientific basis for the biodiversity conservation and development of management regulations for reasonable sustainable utilization of NTFPs.

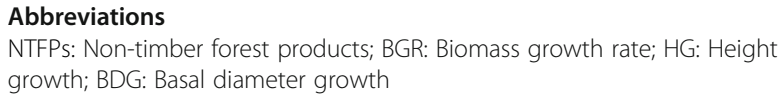

Acknowledgements

Not applicable.

\section{Authors' contributions}

LZY conceived the ideas and designed the study. YM conducted the field experiments. TZ analyzed the data and led the writing of the first draft of the manuscript. QLY and LZY contributed to revising the manuscript. All authors contributed to the drafts and gave final approval for publication.

\section{Funding}

This work was supported by grants from the National Key R \& D Program of China (2016YFC0500302); the National Natural Science Foundation of China (U1808201); Strategic Leading Science \& Technology Programme, CAS (XDA23070100); and the Liaoning Revitalization Talents Program (XLYC1807102).

\section{Availability of data and materials}

Please contact the author for data requests.

\section{Declarations}

Ethics approval and consent to participate

Not applicable.

\section{Consent for publication}

Not applicable.

\section{Competing interests}

The authors declare that they have no competing interests.

\section{Author details}

${ }^{1}$ CAS Key Laboratory of Forest Ecology and Management, Institute of Applied Ecology, Shenyang 110016, China. ${ }^{2}$ Qingyuan Forest CERN, Chinese Academy of Sciences, Shenyang 110016, China. ${ }^{3}$ Agriculture and Rural Bureau of Luanping County, Chengde 068250, China.

Received: 15 April 2021 Accepted: 18 July 2021

Published online: 16 August 2021

\section{References}

Avocèvou-Ayisso C, Sinsin B, Adégbidi A, Dossou G, Damme PV (2009) Sustainable use of non-timber forest products: Impact of fruit harvesting on Pentadesma butyracea regeneration and financial analysis of its products trade in Benin. Forest Ecol Manag 257:1930-1938. https://doi.org/10.1016/j. foreco.2009.01.043

Belcher B, Schreckenberg K (2007) Commercialisation of non-timber forest products: a reality check. Dev Policy Rev 25:355-377. https://doi.org/10.1111/ j.1467-7679.2007.00374.x

Chou P (2019) The utilization and institutional management of non-timber forest products in Phnom Prich wildlife sanctuary, Cambodia. Environ Dev Sustain 21:1947-1962. https://doi.org/10.1007/s10668-018-0113-3

Endress BA, Gorchov DL, Berry EJ (2006) Sustainability of a non-timber forest product: effects of alternative leaf harvest practices over 6 years on yield and demography of the palm Chamaedorea radicalis. Forest Ecol Manag 234:181191. https://doi.org/10.1016/j.foreco.2006.07.020

FAO (2020a) Global Forest Resources Assessment 2020: Main report. Rome. https://doi.org/10.4060/ca9825en

FAO (2020b) Food and Agriculture Organization of the United Nations (FAO): About Non-Wood Forest Products. http://www.fao.org/forestry/nwfp/6388/ en/. Accessed 30 June 2021

Fujikawa T, Miguchi S, Kanada N, Nakai N, Ogata M, Suzuki I, Nakashima K (2005) Acanthopanax senticosus harms as a prophylactic for MPTP-induced Parkinson's disease in rats. J Ethnopharmacol 97:375-381. https://doi.org/10.1 016/j.jep.2004.11.031

Gaoue O, Ticktin T (2008) Impacts of bark and foliage harvest on Khaya senegalensis (Meliaceae) reproductive performance in Benin. J Appl Ecol 45: 34-40. https://doi.org/10.1111/j.1365-2664.2007.01381.x

Geng CF, Gao WL, Zhang SH, Li XM (2013) Construction of Aralia elata bumper crop garden and sprout-harvest technique. Shandong For Sci Tech 43:69-71 (in Chinese)

Guedje NM, Zuidema PA, During H, Foahom B, Lejoly J (2007) Tree bark as a non-timber forest product: the effect of bark collection on population structure and dynamics of Garcinia lucida Vesque. Forest Ecol Manag 240:112. https://doi.org/10.1016/j.foreco.2006.09.029

Han HY, Zheng J, Bai P (2008) Tissue culture and rapid breeding of Acanthopanax senticosus. Shandong Agr Sci 2:18-20 (in Chinese with English abstract)

Hao YF, Gao DW, Fan LL (2018) Artificial reproduction techniques of Aralia elata: research progress. Chin Agr Sci Bull 34:36-42 (in Chinese with English abstract) 
Hernández-Barrios JC, Anten NPR, Martínez-Ramos M (2014) Sustainable harvesting of non-timber forest products based on ecological and economic criteria. J Appl Ecol 52:389-401. https://doi.org/10.1111/1365-2664.12384

Jonsson TH (2006) Terminal bud failure of black cottonwood (Populus trichocarpa) exposed to salt-laden winter storms. Tree Physiol 26:905-914. https://doi.org/10.1093/treephys/26.7.905

Lázaro-Zermeño JM, González-Espinosa M, Mendoza A, Martínez-Ramos M, Quintana-Ascencio PF (2011) Individual growth, reproduction and population dynamics of Dioon merolae (Zamiaceae) under different leaf harvest histories in Central Chiapas, Mexico. Forest Ecol Manag 261:427-439. https://doi.org/1 0.1016/j.foreco.2010.10.028

Liu S, Guo S, Duan JZ, Ren YY (2011) Effects of shading on growth and photosynthetic characteristics of Eleutherococcus senticosus. Ginseng Res 23: 13-15 (in Chinese with English abstract)

Longworth JB, Williamson GB (2018) Composition and diversity of woody plants in tree plantations versus secondary forests in Costa Rican lowlands. Trop Conserv Sci 11:1-13. https://doi.org/10.1177/1940082918773298

Lu DL, Wang GG, Yu LZ, Zhang T, Zhu JJ (2018b) Seedling survival within forest gaps: the effects of gap size, within-gap position and forest type on species of contrasting shade-tolerance in Northeast China. Forestry 91:470-479. https://doi.org/10.1093/forestry/cpy007

Lu DL, Wang GG, Zhang JX, Fang YT, Zhu CC, Zhu JJ (2018a) Converting larch plantations to mixed stands: effects of canopy treatment on the survival and growth of planted seedlings with contrasting shade tolerances. Forest Ecol Manag 409:19-28. https://doi.org/10.1016/j.foreco.2017.10.058

Luo GJ (2003) Cultivation technology of Aralia elata. Northeast Forestry University, China, Dissertation

Nguyen TV, LV JH, Ngo VQ (2021) Factors determining upland farmers' participation in non-timber forest product value chains for sustainable poverty reduction in Vietnam. Forest Policy Econ 126:102424. https://doi. org/10.1016/j.forpol.2021.102424

Qi MM, Li ZW, Yan XF, Wang Y, Lin JX (2015) Research progress in reproduction techniques and pharmacological active components of Aralia elata. Sci Silv Sin 51:96-102 (in Chinese with English abstract)

Rist L, Shanley P, Sunderland T, Sheil D, Ndoye O, Liswanti N, Tieguhong J (2012) The impacts of selective logging on non-timber forest products of livelihood importance. Forest Ecol Manag 268:57-69. https://doi.org/10.1016/j.foreco.2 011.04.037

Ros-Tonen MAF (2000) The role of non-timber forest products in sustainable tropical forest management. Holz Roh Werkst 58:196-201. https://doi.org/1 $0.1007 /$ s001070050413

Schmidt IB, Mandle L, Ticktin T, Gaoue OG (2011) What do matrix population models reveal about the sustainability of nontimber forest product harvest? J Appl Ecol 48:815-826. https://doi.org/10.1111/j.1365-2664.2011.01999.x

Schumann K, Wittig R, Thiombiano A, Becker U, Hahn K (2011) Impact of land-use type and harvesting on population structure of a non-timber forest productproviding tree in a semi-arid savanna, West Africa. Biol Conserv 144:23692376. https://doi.org/10.1016/j.biocon.2011.06.018

Stanley D, Voeks R, Short L (2012) Is non-timber forest product harvest sustainable in the less developed world? A systematic review of the recent economic and ecological literature. Ethnobiol Conserv 1:1-39. https://doi. org/10.15451/ec2012-8-1.9-1-39

Sun T, Zhang GR, Wang Y, Zhang SB (2009) Research progress on chemical composition, pharmacological action and edible value of Aralia elata. Ginseng Res 1:24-25. (in Chinese)

Tian GW, Liu LD, Wang ZL, Shen JH (1999) Studies on the structure, afterripening and cytochemistry of seeds in Eleuthercoccus senticosus. Acta Bot Borealoccident Sin 19:7-13 (in Chinese with English abstract)

Ticktin T (2004) The ecological implications of harvesting non-timber forest products. J Appl Ecol 41:11-21. https://doi.org/10.1111/j.1365-2664.2004. 00859.x

Wahlén CB (2017) Opportunities for making the invisible visible: towards an improved understanding of the economic contributions of NTFPs. Forest Policy Econ 84:11-19. https://doi.org/10.1016/j.forpol.2017.04.006

Wang YW, Duanmu J (2009) Ecological impact of Acanthopanax senticosus on exploitation in Changbai mountain forest. Environ. Sci Manag 34:160-163 (in Chinese with English abstract)

Yan QL, Gang Q, Zhu JJ (2019) Size-dependent patterns of seed rain in gaps in temperate secondary forests, Northeast China. Forests 10:123. https://doi. org/10.3390/f10020123
Yang K, Shi W, Zhu JJ (2013) The impact of secondary forests conversion into larch plantations on soil chemical and microbiological properties. Plant Soil 368:535-546. https://doi.org/10.1007/s11104-012-1535-6

Yu D, Zhou L, Zhou W, Ding H, Dai L (2011) Forest management in Northeast China: history, problems, and challenges. Environ Manag 48:1122-1135. https://doi.org/10.1007/s00267-011-9633-4

Zhang P, Shen HL (2011) Cultivation techniques of Aralia elata planted for edible and medicinal purposes. Nonwood Forest Res 29:69-73 (in Chinese with English abstract)

Zhang T, Yan QL, Wang J, Zhu JJ (2018) Restoring temperate secondary forests by promoting sprout regeneration: effects of gap size and within-gap position on the photosynthesis and growth of stump sprouts with contrasting shade tolerance. Forest Ecol Manag 429:267-277. https://doi. org/10.1016/j.foreco.2018.07.025

Zhao JN, Tan YT, Jiang TT, Lu WX (2016) Pharmacological effects of Aralia elata. Jilin J Tradit Chin Med 36:207-210 (in Chinese with English abstract)

Zhou L, Wang MN, Zhu X, Cheng HM, Wang YX, Du F, Guo LQ (2018) Active ingredients, pharmacological actions, and clinical applications of Acanthopanax senticosus in the central nervous system. J Hunan Univ Chin Med 38:961-964 (in Chinese with English abstract)

Zhu CY, Zhu JJ, Wang GG, Zheng X, Lu DL, Gao T (2019b) Dynamics of gaps and large openings in a secondary forest of Northeast China over 50 years. Ann Forest Sci 76:72. https://doi.org/10.1007/s13595-019-0844-9

Zhu YY, Fu B, Liu J, Wang YK, Xu P, Yan K, Li M, Liu Q (2019a) Sale of wild edible fungi-key influence on the relationship between household livelihood and non-timber forest products utilisation: a case study in the three gorges reservoir area. Forest Ecol Manag 444:1-8. https://doi.org/10.1016/j.foreco.201 9.04 .009

\section{Submit your manuscript to a SpringerOpen ${ }^{\odot}$ journal and benefit from:}

- Convenient online submission

- Rigorous peer review

- Open access: articles freely available online

- High visibility within the field

- Retaining the copyright to your article

Submit your next manuscript at $\boldsymbol{\nabla}$ springeropen.com 